\title{
Effect of calcination process on structural and optical properties of tungsten doped $\mathrm{ZnO}$ nanostructures
}

\author{
${ }^{* 1}$ A. Balamurugan, ${ }^{2}$ M. Sudha, ${ }^{3}$ S. Surendhiran, ${ }^{4}$ V. Devabharathi, ${ }^{5}$ Y.A. Syed Khadar \\ ${ }^{* 1}$ Department of Physics, Government Arts and Science College, Avinashi- 641 654, Tamilnadu (India) \\ ${ }^{2}$ Department of Physics, Government Arts College, Udhagamandalam - 643 002, Tamilnadu (India) \\ ${ }^{3}$ Centre for Nanoscience and Technology, KS Rangasamy College of Technology, Tiruchengode - 637 215, Tamilnadu (India) \\ ${ }^{4}$ Department of Physics, KSR Institute for Engineering and Technology, Tiruchengode - 637 215, Tamilnadu (India) \\ ${ }^{5}$ Department of Physics, KSR Arts and Science College for Women, Tiruchengode - 637 215, Tamilnadu (India)
}

\begin{tabular}{|c|c|}
\hline ARTICLE DETAILS & \multirow{4}{*}{$\begin{array}{l}\text { ABSTRACT } \\
\text { A systematic investigation on the structural, optical and photo catalytic properties of } \\
\text { pure and tungsten (W) doped } \mathrm{ZnO} \text { nanoparticles synthesized by sonochemical } \\
\text { method followed by increased calcinations temperature is presented here. The X-ray } \\
\text { diffraction (XRD) analysis of these samples showed the formation of phase pure } \\
\text { nanoparticles with wurtzite } \mathrm{ZnO} \text { structure. The Ultra violet (UV-Vis) optical studies } \\
\text { showed a blue shift in the absorbance peak spectrum with increasing the doping } \\
\text { concentration of Tungsten. The FESEM imaging analysis reveals the spherical like } \\
\text { morphology with agglomeration and clearly depicts the calcination temperature plays } \\
\text { an important role in morphological formation and variation in agglomeration of the } \\
\text { prepared } Z n O \text { nanostructures. The Rhodamine B (RhB) decomposition rate of the } \\
\text { synthesized pure ZnO and tungsten doped ZnO nanoparticles were studied under the } \\
\text { UV region. In the UV region, synthesized pure ZnO and Tungsten doped ZnO } \\
\text { decomposed RhB dye. However, the RhB decomposition rate obtained using pure } \\
\mathrm{ZnO} \text { was much lower than by doped ZnO. }\end{array}$} \\
\hline $\begin{array}{l}\text { Article History } \\
\text { Published Online: } 15 \text { May } 2020\end{array}$ & \\
\hline $\begin{array}{l}\text { Keywords } \\
\text { Tungsten doped ZnO nanostructures; } \\
\text { Calcination process; Rhodamine B dye; } \\
\text { photocatalyst. }\end{array}$ & \\
\hline $\begin{array}{l}\text { “Corresponding Author } \\
\text { Email: bala.snr[at]gmail.com }\end{array}$ & \\
\hline
\end{tabular}

\section{Introduction}

Interest in the research efforts on $\mathrm{ZnO}$ nanostructures is pushed by means of its quite a number applications in blue and ultraviolet (UV) light emitters regions, transparent conductors, solar cell windows, gas sensors, photovoltaic devices and surface acoustic wave devices [1-6]. Progress made in the area of $\mathrm{ZnO}$ primarily based nanomaterials and devices shows that $\mathrm{ZnO}$ has a top notch viable due to its wide and direct band gap of $3.37 \mathrm{eV}$ and a large excitonic binding energy of $60 \mathrm{meV}$ at room temperature. In the past several years, a number of strategies have been employed to put together $\mathrm{ZnO}$ nanostructures such as Sol-gel, sonochemical, micro emulsion, hydrothermal and chemical coprecipitation methods. In this above mentioned methods, sonochemical method is recognized as opted method to prepare doped $\mathrm{ZnO}$ nanostructures (metal and non-metals) [7-12].

In the case of $\mathrm{ZnO}$ nanostructures, the fundamental limitations are the excessive energy gap, agglomeration, and poor particle dispersability. Researchers have attempted to overcome these issues by altering the structure of $\mathrm{ZnO}$ nanostructures using dopants or some other inhibitors. In fact, surface modification by surfactants has proven beneficial for heading off aggregation, and doping is expected to decrease the energy gap and shift the required excitation wavelength from the UV range to the visible light spectrum [13-16]. Therefore, the doping of the structure of $\mathrm{ZnO}$ nanostructures the usage of appropriate dopants is predicted to improve their affectivity in the photo degradation of organic pollutants and additionally in antibacterial activities [17-24].
In this paper, we discuss about the synthesis of $\mathrm{W}$ doped $\mathrm{ZnO}$ nanostructures via sonochemical root and the impact of calcination temperature on the structural and optical properties of synthesized nanostructures. The optoelectronic and photodegrdation properties of $\mathrm{ZnO}$ nanoparticles are touchy to dopant and calcination temperature. It is consequently vital that the relation among the size and operating conditions be surely understood so that the properties of the nanoparticles may additionally be tuned in accordance to the purposes for which they are synthesized.

\section{Experimental Details}

\subsection{Materials and Methods}

Analytical Reagent (AR) grade zinc acetate $\left(\mathrm{ZnC}_{4} \mathrm{H}_{6} \mathrm{O}_{4}\right.$ $99.99 \%)$, Sodium tungstate $\left(\mathrm{Na}_{2} \mathrm{O}_{4} \mathrm{~W} \cdot{ }_{2} \mathrm{H}_{2} \mathrm{O}-99.99 \%\right)$, sodium hydroxide, double distilled water (DD) were used as precursor materials without further purification for the preparation of pure and tungsten doped $\mathrm{ZnO}$ nanostructures by sonication method.

The Zinc acetate and sodium tungstate were dissolved separately in DD water to obtain $0.5 \mathrm{~mol} / \mathrm{l}$ solutions. Sodium tungstate solution in required stoichiometry was slowly added into vigorously stirred zinc acetate $(100 \mathrm{ml}$ of $0.5 \mathrm{~m})$ solution. After 30 mins, sodium hydroxide solution was slowly added into the above solution and solution was turns to whitish black colour gel type solution. Then this solution was transferred to sonication chamber and sonicated for 30 mins with $40 \mathrm{~Hz}$ power. The resultant product was dried at $100^{\circ} \mathrm{C}$ for 12 hours (h) and calcined at 400,600 and $800^{\circ} \mathrm{C}$ for $3 \mathrm{~h}$. The pure $\mathrm{ZnO}$ nanostructures were also prepared by the same procedure without the addition of sodium tungstate solution. The schematic 
representation of preparation methods were clearly shown in figure 1.

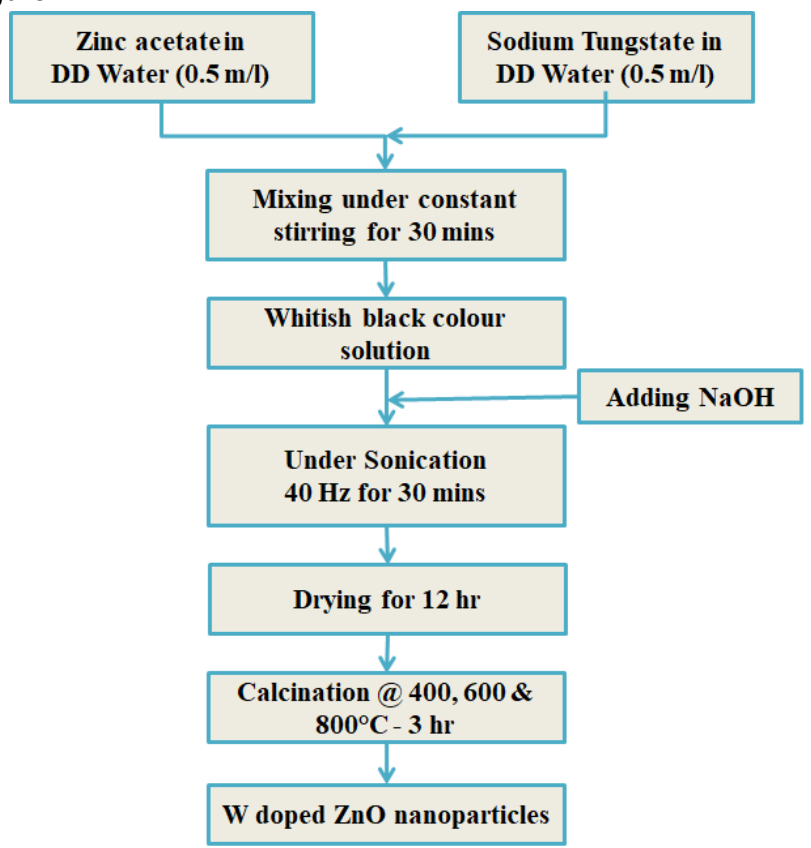

Fig. 1. Schematic representation of synthesis process of $\mathrm{W}$ doped $\mathrm{ZnO}$ nanostructures

\subsection{Characterization of $\mathrm{ZnO}$ nanostructures}

Characterization Techniques such as X-Ray Diffraction (XRD), UV-Visible spectroscopy (UV-Vis), FESEM-coupled with EDX, particle size analyzer (PSA) were used to characterize the prepared $\mathrm{W}$ doped $\mathrm{ZnO}$ nanostructures.

To pick out the structural identification and the common crystallite dimension of the organized $\mathrm{W}$ doped $\mathrm{ZnO}$ nanostructures used to be used with the aid of X-ray diffractometer (X'Pert PRO; PANalytical, the Netherlands). CuKa radiation $(\lambda=1.5406 \AA)$ used to be as a source to analyses the organized $\mathrm{ZnO}$ nanostructures at the $2 \theta$ from $10^{\circ}$ to $80^{\circ}$ with $2 \theta$ step of $0.02^{\circ}$. The UV absorption spectra of $W$ doped $\mathrm{ZnO}$ nanostructures have been recorded the usage of UV-visible (UV-Vis) Spectrophotometer (Cary 8454; Agilent, Singapore) operated from the $180-800 \mathrm{~nm}$ spectral regions at a step dimension of $5 \AA$. The dispersed $\mathrm{ZnO}$ nanostructure $(0.1$ $\mathrm{mg}$ of $\mathrm{W}$ doped $\mathrm{ZnO}$ nanostructures used to be dispersed in 5 $\mathrm{ml}$ double deionized water and sonicated for few minutes to create uniform dispersion) was taken in a cuvette. The particle size distribution and average particle size of the $\mathrm{W}$ doped $\mathrm{ZnO}$ nanostructures had been carried out with a submicrometre particle measurement analyser (Nanophox; Sympatec, Zellerfeld, Germany) the use of dynamic light-scattering (DLS) technique. Field Emission Scanning electron microscope (FESEM; JSM-6790 LS; JEOL, forty Japan) was once used to analyse the surface morphology of the prepared $\mathrm{W}$ doped $\mathrm{ZnO}$ nanostructures.

\subsection{Photocatalytic degradation of Rhodamine B dye}

The photocatalytic degradation of RhB dye in the existence of $\mathrm{W}$ doped $\mathrm{ZnO}$ nanoparticles beneath sun light irradiation was once analysed as follows. Briefly, a $100 \mathrm{mg}$ of organized $\mathrm{ZnO}$ nanoparticles had been introduced into a $100 \mathrm{ml}$ of aqueous $\mathrm{RhB}$ solution $(50 \mathrm{mg} / \mathrm{L}$ ) and stirred for $10 \mathrm{~min}$ to get clear suspension. Then appropriate volume of the supernatant RhB answer used to be taken with 15 minutes time interval to understand the awareness of RhB the use of UV-Vis spectrophotometer via the usage of absorption capability. Dye degradation successfully of $\mathrm{ZnO}$ nanoparticles beneath considered mild was as soon as determined the usage of the below relation $[25,26]$.

Dye degradation efficiency $\eta=\left(1-\frac{c}{c_{0}}\right)$ where $\mathrm{C}$ and $\mathrm{C}_{0}$ are final and initial concentration of $\mathrm{RhB}$ solution.

\section{Result and Discussion}

The powder XRD patterns have been used to decide the effects of the addition of $\mathrm{W}$ and calcination temperature on the crystal phase and crystallinity of $\mathrm{ZnO}$. Fig. 2 suggests the XRD patterns of pure $\mathrm{W}$ added $\mathrm{ZnO}$ nanostructures with different calcination temperatures. All the XRD patterns showed a hexagonal wurtzite crystal structure and high crystallinity of $\mathrm{ZnO}$ nanostructures. The diffraction peaks of the $\mathrm{ZnO}$ (Fig. 2) are sharp and intense, revealing the highly crystalline character of the $\mathrm{ZnO}$ sample, whilst the diffraction peaks of the $\mathrm{W}$ added $\mathrm{ZnO}$ are large and susceptible peaks

The XRD patterns of all the $\mathrm{W}$ added $\mathrm{ZnO}$ nanostructures are almost comparable to that of $\mathrm{ZnO}$, suggesting that there is no alternate in the crystal structure upon tungsten doping process. However, it can be indicated that $\mathrm{W} 6+$ ions are uniformly dispersed on $\mathrm{ZnO}$ nanostructures in the form of fantastically dispersedWO3 clusters. It is interesting to observe that the particles size of $\mathrm{W}$ added $\mathrm{ZnO}$ is a whole lot smaller as compared with that of the pure $\mathrm{ZnO}$ compared with our previously reports $[27,28]$. But when the calcination temperature increased to 600 and $800^{\circ} \mathrm{C}$, crystal size linearly increased which prompted the growth of nanocrystals grains. The another reason for this could be that some W6+entered into the crystal lattice of $\mathrm{ZnO}$ and suppressed the growth of the $\mathrm{ZnO}$ crystal due to the similar radius of $\mathrm{W}^{6+}$ and $\mathrm{Zn}^{2+}$

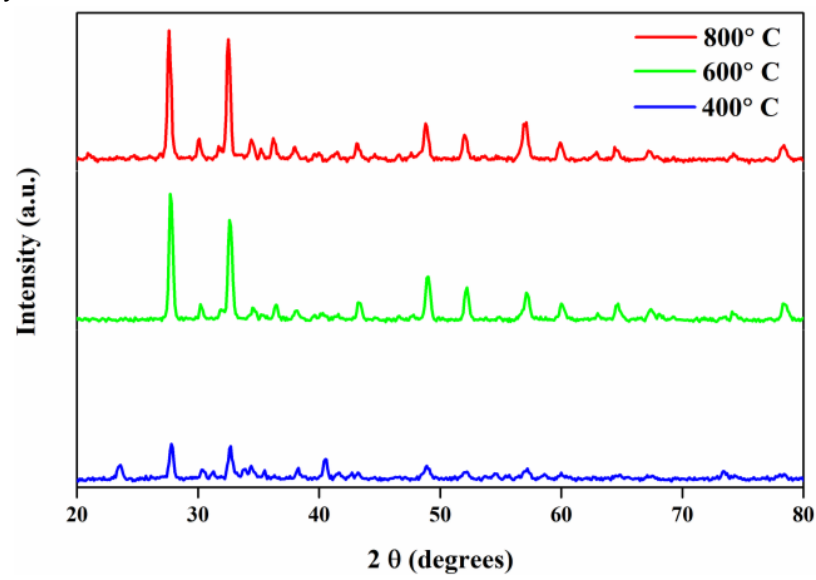

Fig. 2. XRD Pattern of $\mathrm{W}$ doped $\mathrm{ZnO}$ nanostructures after calcined at 400,600 and $800^{\circ} \mathrm{C}$

We have carried a relative analysis of average crystallite sizes (D) of W doped ZnO nanostructures by means of DebyeScherrer formula [29, 30]. The common crystallite size (D) of samples have been determined the use of full width at half of most (FWHM) of the most extreme diffraction peak (101) thru the Debye-Scherrer components which is given below

$\mathrm{D}=\mathrm{KN} /(\beta \cos \theta)$ 
Where $D$ is crystallite size, $\theta$ is glancing factor $(k=0.9)$ and $\beta$ is full width at half maxima (FWHM) of the peak. Using above equation we have decided crystallite dimension (D) of $\mathrm{W}$ doping with $\mathrm{ZnO}$ nanostructures.

The average crystallite sizes (D) have been calculated using the Debye-Scherrer formulation as given above which are lying in the range of $17.1,20.5$ and $21.7 \mathrm{~nm}$ for 400, 600 and $800^{\circ} \mathrm{C}$ calcinated $\mathrm{W}$ doped $\mathrm{ZnO}$ nanostructures respectively. The average crystalline sizes were gradually increased while calcination temperature increased in $\mathrm{ZnO}$ [31-33].

The surface morphology of the $\mathrm{W}$ doped $\mathrm{ZnO}$ nanostructures had been captured and discussed thru Field Emission Scanning electron microscopy (FESEM) and shown in fig. 3 (respectively for 400, 600 and $800^{\circ} \mathrm{C}$ calcinated nanostructures). It was once located to be spherical in nature as proven in Fig. 2 (a) for $400 \mathrm{C}$ calcinated $\mathrm{W}$ doped $\mathrm{ZnO}$ nanostructures. Afterwards, the morphology have been started to agglomerate with nearest particles when tge calcination temperature increased to $800^{\circ} \mathrm{C}$ on $\mathrm{W}$ doped $\mathrm{ZnO}$ nanostructures fig 3 (b \& c for 600 and $800^{\circ} \mathrm{C}$ calcinations). XRay florescence (XRF) spectral evaluation has been carried out to confirm the chemical composition of the sample. Table. 1 shows the EDX spectra of $\mathrm{W}$ doped $\mathrm{ZnO}$ which confirm that as organized nanostructures include solely $\mathrm{Zn}, \mathrm{O}$ and $\mathrm{W}$ ions phase in the sample. These effects are effectively agreed with our XRD statistics and no different impurity phases have been located within $\mathrm{W}$ doped $\mathrm{ZnO}$ nanostructures.

\begin{tabular}{lll}
\multicolumn{3}{l}{ Table 1 XRF analysis of Ni doped ZnO nanostructure } \\
\hline Sample & Elements & Atomic (\%) \\
\hline ZnO: W-400 & O & 53.7 \\
& Zn & 22.9 \\
& W & 23.2 \\
ZnO: W-600 & O & 51.1 \\
& Zn & 24.4 \\
ZnO: W-800 & W & 24.5 \\
& O & 49.6 \\
& Zn & 25.0 \\
& W & 25.4 \\
\hline
\end{tabular}
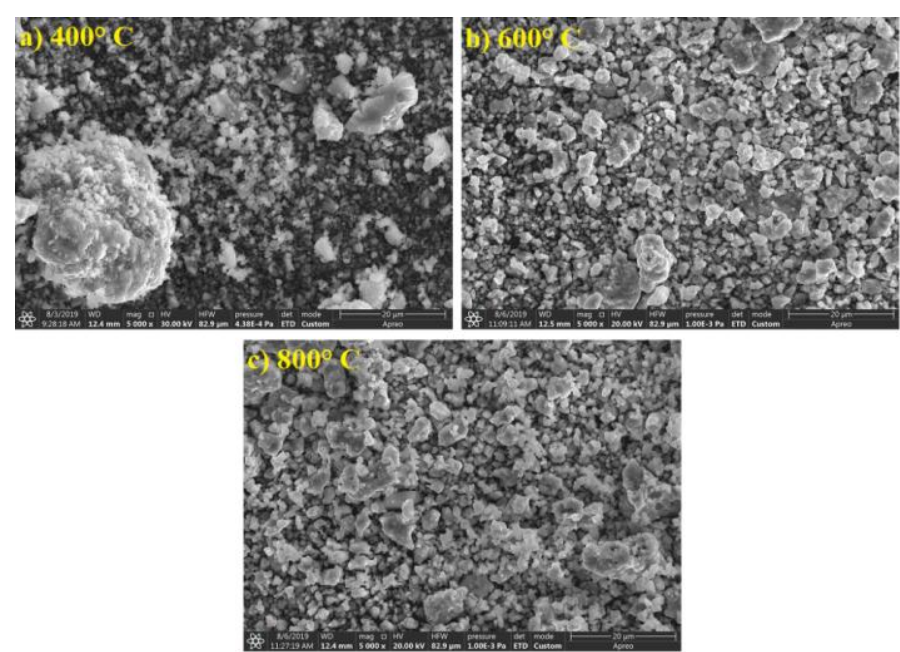

Fig. 3. FESEM image of $\mathrm{W}$ doped $\mathrm{ZnO}$ nanostructures $(\mathrm{a}, \mathrm{b}$ and $\mathrm{c}$ respectively for calcination at 400,600 and $800^{\circ} \mathrm{C}$ )

The FTIR spectra of the $\mathrm{W}$ doped $\mathrm{ZnO}$ nanostructures are depicted in Figure 4. As can be seen, the spectra showed a strong vibrational band at $551 \mathrm{~cm}^{-1}$, referring to the stretching vibration of $\mathrm{Zn}-\mathrm{O}$ bonds. In addition to this peak, the spectra contained a peak at $1446 \mathrm{~cm}^{-1}$, which could be ascribed to the $\mathrm{C}=\mathrm{O}$ bond stretching of the carboxylic groups and a peak at $2918 \mathrm{~cm}^{-1}$, which was indicative of the $\mathrm{C}-\mathrm{H}$ bonds. Consistent with the present study, the findings of Mote have denoted the observation of the $\mathrm{Zn}-\mathrm{O}$ stretching mode at $600-400 \mathrm{~cm}^{-1}$ and the $\mathrm{N}-\mathrm{H}$ stretching vibration at $3600-3400 \mathrm{~cm}^{-1}$ in a study regarding $\mathrm{W}$-doped $\mathrm{ZnO}$ nanostructures [34-35].

The average particle diameter $\left(d_{50}\right)$ of the prepared $W$ doped $\mathrm{ZnO}$ nanostructures have been degrees around $45 \mathrm{~nm}$ to $75 \mathrm{~nm}$ and actual values of average particle diameter measurement is given in fig. 5 (respectively for 400, 600 and $800^{\circ} \mathrm{C}$ calcinated $\mathrm{W}$ doped $\mathrm{ZnO}$ nanostructures).

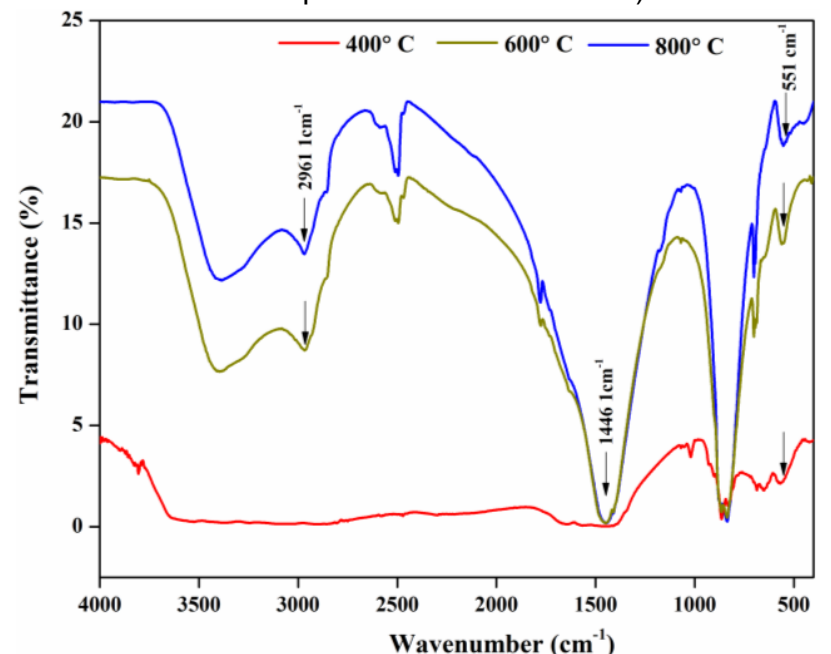

Fig. 4. FTIR Spectra of $\mathrm{W}$ doped $\mathrm{ZnO}$ nanostructures for 400,600 and $800^{\circ} \mathrm{C}$ calcination temperatures

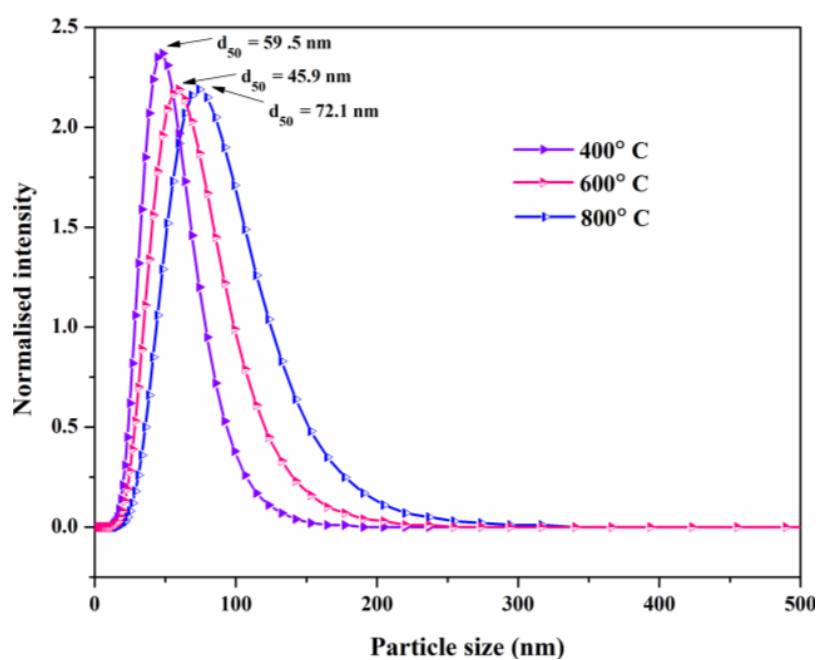

Fig. 5. Average particle diameter distribution curve of $\mathrm{W}$ doped $\mathrm{ZnO}$ nanostructures for 400,600 and $800^{\circ} \mathrm{C}$ calcination temperatures

Since the size of the nanoparticles is most necessary ruling property for optical and electrical properties of the nanostructures, in a similar way for all different applications in accordance to quantum confinement effect. The average particle diameter distribution of 400,600 and $800^{\circ}$ Calcinated W doped $\mathrm{ZnO}$ nanostructure are 45.9, 59.5, and $72.1 \mathrm{~nm}$ respectively. The sizes of the nanostructures are step by step increased according to when calcination temperature increased to $800^{\circ} \mathrm{C}$ in $\mathrm{ZnO}$. The above results clearly indicate that the $\mathrm{W}$ 
doping with $\mathrm{ZnO}$ play a dominant role in structural and optical properties of the prepared nanostructures.

The UV absorption spectra of $\mathrm{W}$ doped $\mathrm{ZnO}$ nanostructures have been recorded in the range $200-800 \mathrm{~nm}$ of electromagnetic spectrum. The uv-vis spectra of $\mathrm{W}$ doped $\mathrm{ZnO}$ nanostructures showed an extensive deviation in absorption depth at the blue region (lower wavelength region) with expand when calcination temperature increased which is without a doubt seen in Fig 5. The large difference in the absorption intensity of $\mathrm{W}$ doped nanostructures due to calcination temperature suggests that absorbs more visible light and so can act as a better photocatalyst underneath visible light irradiation. It is assumed that superior optical recreation is due to make bigger in surface imperfections due to doping in $\mathrm{ZnO}$ nanostructures [36-39].

An enlargement in absorption intensity in blue region is attributed to extra pronounce doping of $\mathrm{ZnO}$ nanostructures with $W$ ions and while increase in calcination temperature. Doping of $\mathrm{W}$ with $\mathrm{ZnO}$ provides defect locations in the neighbourhood of valence band and reduces the fantastic band gap of $\mathrm{ZnO}$ nanostructures. When UV-vis light is passed through prepared nanostructures the electron-hole pair is generated inside the fine band gap. It's capacity that the electron waft takes location from defect valence state to defect conduction state. This transition requires much lower energy than band hole of $\mathrm{ZnO}$ [40].

The optical band gap energies of $\mathrm{W}$ doped $\mathrm{ZnO}$ nanostructures had been determined the usage of the Tauc relationships given below [41-42]:

$$
\boldsymbol{\alpha h} \boldsymbol{v}=\boldsymbol{A}\left(\boldsymbol{h} v-\boldsymbol{E}_{g}\right)^{\boldsymbol{n}}
$$

Where $\alpha$ is the absorption coefficient $(\alpha=2.303 \mathrm{~A} / \mathrm{t}$, where $A$ is absorbance and $t$ is thickness of the cuvette) and $h, v$ and $E_{g}$ are Planck's constant, photon frequency and optical band gap energy, respectively.

The exponent $(n)$ have the values $1 / 2,3 / 2,2$ and 3 equivalent to the allowed direct, forbidden direct, allowed indirect and forbidden indirect transitions respectively.
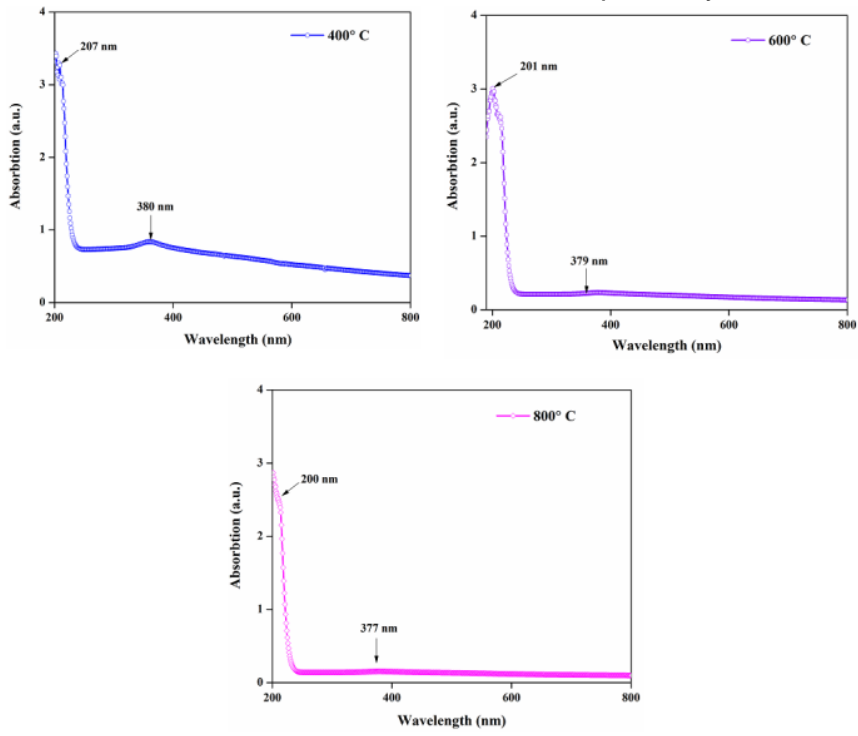

Fig. 6. UV-Vis absorption spectra of $\mathrm{W}$ doped $\mathrm{ZnO}$ nanostructures ( $\mathrm{a}, \mathrm{b}$ and $c$ respectively for calcination at 400,600 and $800^{\circ} \mathrm{C}$ )
The optical band gap was once various from 3.39, 3.35 and $3.31 \mathrm{eV}$ for exclusive concentrations of $\mathrm{W}$ doped $\mathrm{ZnO}$ nanostructures. The markdown in the bandgap with the thermal treatment increased may want to be regarded as the introduction of $\mathrm{W}$ states in the pinnacle of valence band of $\mathrm{ZnO}$ nanostructures. These results also agreed with the suggested data (earlier reports) [43-45].

A foremost amount of pollutants in contaminated water is from synthetic textile dyes and industrial dyes. Rhodamine B dye is one of basically used dyes in the cloth industries consequently it is appreciably studied as a typical water pollutant and having probabilities to make health hazardless for human being [46]. The degradation of Rhodamine $B$ in the presence of organized $\mathrm{ZnO}$ nanostructures under solar light irradiation used to be studied for the length of 90 mins. Fig. 7 (a) (b) and (c) suggests the time constructed UV-Vis absorption spectrum of Rhodamine $\mathrm{B}$ dye in presence of $\mathrm{W}$ doped $\mathrm{ZnO}$ nanostructures which was calcinated at different temperatures, respectively underneath the Sun light irradiation. It is mentioned that UV absorption of Rhodamine B dye at $554 \mathrm{~nm}$ falls rapidly with growing period which published that $\mathrm{W}$ doped $\mathrm{ZnO}$ nanostructures can easily oxidize the Rhodamine $B$ dye underneath solar light illumination.

Moreover, it is genuinely suggests that the photocatalytic assignment of $600^{\circ} \mathrm{C}$ calcinated $\mathrm{W}$ doped $\mathrm{ZnO}$ is substantially higher than that 400 and $800^{\circ} \mathrm{C}$ calcinated $\mathrm{W}$ doped $\mathrm{ZnO}$ nanostructures. The photocatalytic degradation effectively of $\mathrm{W}$ doped $\mathrm{ZnO}$ nanostructures for the length of 90 mins on Rhodamine B dye degradation are 81.7, 93.8 and $90.77 \%$ respectively for 400,600 and $800^{\circ} \mathrm{C}$ calcinated samples.
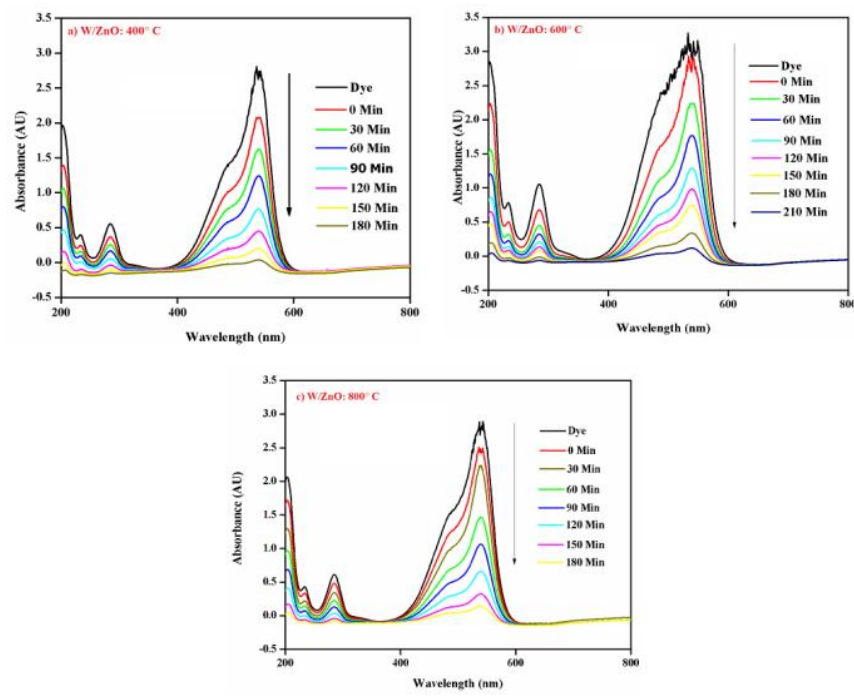

Fig. 7. Photocatalytic activity of $\mathrm{W}$ doped $\mathrm{ZnO}$ nanostructures towards Rhodamine $B$ (a, b and c respectively for calcination at 400,600 and $800^{\circ} \mathrm{C}$

In the visible light place the $600^{\circ} \mathrm{C}$ calcinated $\mathrm{W}$ doped $\mathrm{ZnO}$ nanostructures degraded the Rhodamine $\mathrm{B}$ dye quicker than the other $\mathrm{ZnO}$ nanostructures. The motive is being extended in surface defects on account of doping leading to improved absorption in the visible region. Once the above samples are irradiated to visible light (sun light), electron hole pair is generated. The electron so generated disrupts the conjugation in the dye and for that reason the decomposition of dye and the hole so generated creates $\mathrm{OH}$ from water which 
again leads to degradation of dye. The plot of absorption vs. wavelength at a range of instances for the photo degradation of Rhodamine B dye is represented in Fig. 7. It is seen in sketch that $\mathrm{W}$ doped $\mathrm{ZnO}$ degrades the $45 \%$ of dye in simply 15 minutes as in contrast to $400^{\circ} \mathrm{C}$ and $800^{\circ} \mathrm{C} \mathrm{W}$ doped $\mathrm{ZnO}$ which takes almost 37 minutes to degrade $50 \%$ of dye. $\mathrm{ZnO}$ nanostructures with the aid of doping can be used as workable photo catalytic retailers for degradation of dyes and different harmful organic compounds.

\section{Conclusion}

In order to improve the photodegrdation of dye pollutant under sun light illumination, $\mathrm{W}$ doped $\mathrm{ZnO}$ nanostructures with different calcination temperature was synthesized using sonication method. Zinc oxide nanostructures are a universal photocatalyst. The above synthesized samples proved to be more tremendous photocatalysts than $\mathrm{ZnO}$ by in contrast with until now reports. The doped $\mathrm{ZnO}$ nanoparticles show to be environment friendly materials for degrading contaminated colored waste water for reusing in cloth industry and calcination temperature shows an excellent influence on structural and optical properties of the prepared nanostructures. Hence the synthesized doped nanoparticles prove to be higher marketers for environmental detoxing of organic compounds, detrimental dyes such as Rhodamine B, Rhodamine 60G, Methylene blue, and some metals too from waste water.

\section{References}

1. Aleksandra Sosna-Głębska et al., (2019) Review on Metallic Oxide Nanoparticles sand Their Application in Optoelectronic Devices. Acta Innovations 2300-5599 30:5-15 5

2. Su-Eon Jin et al., (2019) Photocatalytic antibacterial application of zinc oxide nanoparticles and self-assembled networks under dual UV irradiation for enhanced disinfe. International Journal of Nanomedicine 14:1737-1751

3. Anja Verbic et al., (2019) Zinc Oxide for Functional Textile Coatings: Recent Advances. Coatings 9:550 2- 26

4. Josue I. Garcia-Lopez et al., (2019) Foliar Application of Zinc Oxide Nanoparticles and Zinc Sulfate Boosts the Content of Bioactive Compounds in Habanero Peppers. Plants 8, 254 :320

5. Jinhuan Jiang et al., (2018) The Advancing of Zinc Oxide Nanoparticles for Biomedical Applications Bioinorganic Chemistry and Applications. 1062562:18

6. Baskaran Divya et al., (2018) Chemical Synthesis of Zinc Oxide Nanoparticles and Its Application of Dye Decolourization. Int. J. Nanosci. Nanotechnol., 14: 267-275

7. Yendry Regina Corrales Ureña et al., (2015) In situ sonochemical synthesis of $\mathrm{ZnO}$ particles embedded in a thermoplastic matrix for biomedical applications. Materials Science and Engineering C 49 : 58-65

8. Agnieszka Kołodziejczak-Radzimska et al., (2014) Zinc Oxide-From Synthesis to Application. A Review Materials 7:2833-2881

9. Varsha Srivastava et al., (2013) Synthesis, characterization and application of zinc oxide nanoparticles $(\mathrm{n}-\mathrm{ZnO})$ Ceramics International 39 9803-9808

10. V. Kavitha et al., (2019) Structural, optical and electrical studies on zinc doped barium strontium titanate as photoanode for DSSC device, Materials Today: Proceedings DOI: 10.1016/j.matpr.2019.05.437

11. V. Kavitha et al., (2020) Optical and structural properties of tungsten-doped barium strontium titanate, Materials Today: Proceedings, 23:1, 12-15, DOI: 10.1016/j.matpr.2019.05.351

12. Yin Zhang, Tapas R. Nayak, Hao Hong, and Weibo Cai (2013) Biomedical Applications of Zinc Oxide Nanomaterials. Curr Mol Med. 13(10): 1633-1645.

13. Dušan Nohavica et al., (2010) ZnO Nanoparticles And Their Applications - New Achievments . Nanocon 12- 14. 10. Olomouc, Czech Republic, EU

14. Pelangi Eka Yuwita et al., (2019) Structural, Optical, and Magnetic Properties of Mn-doped ZnO Nanoparticles Synthesized by Coprecipitation Method. Materials Science and Engineering $515: 012065$

15. U. Sachin Varma et al., (2018) Precipitation as a tool for Effective Doping of Magnesium in Zinc Oxide: Studies on Structural, Optical and Photocatalytic Properties.Rasayan. J.Chem. 11 :1491-1500
16. Gebretinsae Yeabyo Nigussie et al., (2018) Antibacterial Activity of Ag-Doped $\mathrm{TiO}_{2}$ and Ag-Doped $\mathrm{ZnO}$ Nanoparticles. International Journal of Photoenergy 5927485: 1-7

17. D. Sathes Kumar et al., (2018) Violet Color Emitting Cd doped $\mathrm{ZnO}$ Nanoparticles for UV Sensor Applications. IJET. 4 2:904:908

18. Shakeel Ahmad Khan et al., (2017) Synthesis, characterization and evaluation of biological activities of manganese-doped zinc oxide nanoparticles. TJPR 16 (10): 2331-2339

19. S.A.Khan et al., (2017) Comparative Synthesis, Characterization of $\mathrm{Cu}$-Doped $\mathrm{ZnO}$ Nanoparticles and their Antioxidant, Antibacterial, Antifungal and Photocatalytic Dye Degradation Activities Digest Journal of Nanomaterials and Biostructures 12:3:. 877 - 889

20. Pricilla Jeyakumari et al., (2017) Structural, Optical and Antibacterial Activity of Pure and Cadmium Doped Zinc Oxide Nano Particles. IOSR-JAP. 2278-4861: 80-86

21. V.D. Mote et al., (2015) Structural, optical and antibacterial properties of yttrium doped ZnO nanoparticles Cerâmica 61: 457-461

22. Anh-Thu Thi Do et al., (2014) Effects of palladium on the optical and hydrogen sensing characteristics of Pd-doped ZnO nanoparticles. Beilstein J. Nanotechnol. 5: 1261-1267

23. B. Sankara Reddy et al., (2013) Physical and magnetic properties of (Co, $\mathrm{Ag})$ doped $\mathrm{ZnO}$ nanoparticles J Mater Sci: Mater Electron 24:5204-5210.

24. Jagpreet Singh et al., (2019) Corrigendum to the effect of Manganese Doping on Structural, Optical, and Photocatalytic Activity of Zinc Oxide Nanoparticles. Composites Part B 165 :823

25. T.T. Nguyen et al., (2019) Preparation, Characterization and Photocatalytic Activity of La-Doped Zinc Oxide Nanoparticles. Materials $12: 1195$

26. S. Senthil et al., (2018) Effect of chromium doping on structural, optical and photocatalytic properties of $\mathrm{ZnO}$ nanoparticles. Optoelectronics and Advanced Materials Rapid Communications. 12 5-6:. 353 - 359

27. Siti Nur Aqilah Sulaiman et al., (2018) Effects of photocatalytic activity of metal and non-metal doped $\mathrm{TiO}_{2}$ for Hydrogen production enhancement - A Review. IOP Conf. Series: Journal of Physics: 1027012006

28. S. Ezhil Arasi et al., (2018) Effect of samarium $\left(\mathrm{Sm}^{3+}\right)$ doping on structural, optical properties and photocatalytic activity of titanium dioxide nanoparticles. Journal Of Taibah University For Science, 2: 186-190

29. K.C. Suresh et al., (2020) Evaluation of structural, optical and morphological properties of Nickel oxide nanoparticles for Multi-functional applications, Inorganic and Nano-Metal Chemistry DOI: 10.1080/24701556.2020.1770793 
30. Cauê Ribeiro et al., (2017) The interplay between morphology and photocatalytic activity in $\mathrm{ZnO}$ and $\mathrm{N}$-doped $\mathrm{ZnO}$ crystals Materials and Design $120: 363-375$

31. R.Jeyachitra et al., (2016) Effect of Ni doping on structural, optical and photocatalytic properties of $\mathrm{Zn}_{1-x} \mathrm{Ni}_{x} \mathrm{O}$ nanoparticles prepared by different $\mathrm{pH}$ conditions, Journal of advance chemistry 12 6:4097-4107

32. Yang Wang et al., (2014) the Effects of Doping Copper and Mesoporous Structure on Photocatalytic Properties of $\mathrm{TiO}_{2}$ Journal of Nanomaterials. 178152:1- 7

33. Anh-Thu Thi Do et al., (2014) High performance Ce-doped $\mathrm{ZnO}$ nanorods for sunlight-driven photocatalysis. Beilstein J. Nanotechnol. 4, 5: 1261-1267.

34. Dipti Vayaa et al., (2010) Study of synthesis and photocatalytic activities of Mo doped ZnO. Chem. Pharm. Res. 2(3):269-273

35. Kayode Adesina Adegoke et al., (2019) Synthesis, characterization and application of $\mathrm{CdS} / \mathrm{ZnO}$ nanorods heterostructure for the photodegradation of Rhodamine B dye .Materials Science for Energy Technologies 2 :329-33

36. Adeel Riaz et al., (2019) Photocatalytic and Photostability Behavior of $\mathrm{Ag}$ and or Al-Doped ZnO Films in Methylene Blue and Rhodamine B Under UV-C Irradiation. Coatings 9: 202

37. Gaurav Hitkari et al., (2017) Synthesis, Characterization and Visible Light Degradation of Organic dye by Chemically Synthesized $\mathrm{ZnO} / \mathrm{y}-\mathrm{Fe}_{2} \mathrm{O}_{3}$ Nanocomposites IJARSET4 5 :3960-3965

38. M. Sudha et al., (2020) Influence of synthesis methods on various properties of Zinc oxide nanostructures, The International journal of analytical and experimental model analysis, $12: 1326-1338$

DOI: 18.0002.IJAEMA.2020.V12I1.200001.015095

39. Patrícia Gonçalves et al., (2017) Evaluation of the Photocatalytic Potential of $\mathrm{TiO}_{2}$ and $\mathrm{ZnO}$ Obtained by
Different Wet Chemical Methods Materials Research 20 (2)n: 181-189

40. Karnaji et al., (2017) Photodegradation of Rhodamine B by using $\mathrm{ZnFe}_{2} \mathrm{O}_{4} \quad$ Nanoparticles Synthesized through Precipitation Method. Materials Science and Engineering 202 : 012044

41. Ivan Mouritys Pereira Silvaa et al., (2016) Different dye degradation mechanisms for $\mathrm{ZnO}$ and $\mathrm{ZnO}$ doped with $\mathrm{N}$ (ZnO:N). Journal of Molecular Catalysis A: Chemical 417 : 89-100

42. Haiqing Yao et al., (2016) High-performance photocatalyst based on nanosized ZnO-reduced graphene oxide hybrid for removal of Rhodamine $B$ under visible light Irradiation. AIMS Materials Science, 3(4): 1410-1425.

43. M. Sudha et al., (2019) Synthesis and Characterization of Lanthanum added ZnO Nanostructures, Journal of Information and Computational Science 9;12, 1548-7741 DOI:10.12733.JICS.2019.V9I12.535569.11243

44. K.C. Suresh et al., (2019) ZnO nanoparticles: Biosynthesis and characterization of its Multifunctional property Journal of Information and Computational Science 9:12, 1548-7741 DOI: DOI:10.12733.JICS.2019.V9I12.535569.11244

45. Balamurugan et al., (2019) 'Hydrothermal synthesis of samarium $(\mathrm{Sm})$ doped cerium oxide $\left(\mathrm{CeO}_{2}\right)$ nanoparticles: Characterization and antibacterial activity', Materials Today: Proceedings, DOI: 10.1016/j.matpr.2019.08.217

46. M. Sudha et al., (2020) Sonochemical synthesis of Nickel doped $\mathrm{ZnO}$ Nanostructures for Environmental Remediation, RESEARCH REVIEW International Journal of Multidisciplinary, 05:05, 11-16, DOI: $10.5281 /$ zenodo.3832132 